\title{
Temporal integration in Pavlovian appetitive conditioning in rats
}

\author{
KeNNETH J. LEISING \\ University of California, Los Angeles, California \\ Kosuke SAwa \\ Senshu University, Tokyo, Japan \\ AND \\ AARON P. BLAISDELL \\ University of California, Los Angeles, California
}

\begin{abstract}
We used an appetitive sensory preconditioning procedure to investigate temporal integration in rats in two experiments. In Phase 1, rats were presented with simultaneous compound trials on which a 10 -sec conditioned stimulus (CS) X was embedded within a 60-sec CS A. In Group Early, CS X occurred during the early portion of CS A, whereas in Group Late, CS X occurred during the latter portion of CS A. In Phase 2, CS X was paired simultaneously with sucrose. On a subsequent test with CS A, the rate of magazine entries peaked during the early portions of the stimulus in Group Early and during the latter portions of the stimulus in Group Late (Experiments 1 and 2). Similar response peaks were not observed on tests with a control stimulus that had been presented in compound with a stimulus that did not signal reward (Experiment 2).
\end{abstract}

In the framework of many contemporary associative learning theories, the relationship between paired stimuli is encoded as a summary statistic, such as associative strength between a conditioned stimulus (CS) and an unconditioned stimulus (US) (e.g., Mackintosh, 1975; Pearce, 1987; Pearce \& Hall, 1980; Rescorla \& Wagner, 1972; Wagner, 1981). Although these models successfully capture many aspects of conditioning, they also exhibit many shortcomings. For example, they are demonstrably poor at dealing with trial-order effects, such as recency-toprimacy shifts and memory integration (Pineño \& Miller, 2005; Urushihara, Wheeler, \& Miller, 2004; Wheeler, Stout, \& Miller, 2004). Furthermore, there is a large body of evidence that associations encode more than simply the associative strength between stimuli. During associative learning, properties of the cue (CS or discriminative stimulus) and the outcome (US or reinforcer) have been shown to be encoded. These properties include qualitative attributes of the cue (Holland, 1980) and of the outcome (Blaisdell, Denniston, \& Miller, 1997; Holland, 1988; Jenkins \& Moore, 1973), and the cue-outcome spatial (Blaisdell \& Cook, 2005; Sawa, Leising, \& Blaisdell, 2005; Stickney \& Donahoe, 1983), causal (Blaisdell, Sawa, Leising, \& Waldmann, 2006; Perales, Catena, \& Maldonado, 2004), and temporal (Honig, 1981; Miller \& Barnet, 1993; Roberts, 1981; Savastano \& Miller, 1998) relationships. Sufficient evidence has accumulated that questions the isolated summary statistic and supports the conclusion that a rich representation is encoded during the conditioning episode.

In addition to their role in the encoding of event representations and relationships, associative processes also play a role in the integration of larger cognitive representations. In particular, higher order conditioning (e.g., second-order conditioning and sensory preconditioning) has been shown to link event relationships together in piecemeal fashion (Gewirtz \& Davis, 1998, 2000; Savastano \& Miller, 1998). Higher order conditioning is the mediation of a conditioned response to one CS that has not been paired with a US by another CS that has been paired with the US. For example, in sensory preconditioning, two neutral stimuli, CS2 and CS1 (e.g., audiovisual cues), are presented together to establish a CS2-CS1 association. Subsequently, CS1 is paired with a biologically significant US, such as food or shock, thereby establishing a CS1-US association. The established CS2-CS1 and CS1-US associations mediate the development of a conditioned response to CS2, despite its never having been paired directly with the US (Brogden, 1939). In a second-order conditioning procedure, the order of training is reversed in such a way that CS1 is paired with the US before CS2 is paired with CS1. These procedures allow CS1, a common element to both associations, to mediate an associative link between CS2 and the US. A common 
feature to both procedures is that CS1 has a first-order relationship to the US, whereas CS2 has a second-order relationship to the US. If spatial, temporal, and causal information are encoded as part of the association between paired events, then higher order conditioning may mediate the integration of this information into larger cognitive representations.

Matzel, Held, and Miller (1988) proposed the hypothesis that higher order conditioning serves as a mechanism whereby cognitive representations can be built. Using a sensory preconditioning procedure in rats, Matzel et al. paired CS2 with CS1 with a forward relationship in Phase 1 followed by pairing CS1 with a footshock US with a backward relationship in Phase 2. When tested on CS1, rats showed little conditioned suppression; that is, the backward conditioning deficit was obtained (see Pavlov, 1927, p. 27). When tested on CS2, however, rats showed a large amount of conditioned suppression. Matzel et al. hypothesized that the rats had encoded the temporal relationship between CS2 and CS1 and between CS1 and the US. That is, the rats had formed a temporal map (Honig, 1981) encoding the order and temporal distance between the paired events. These temporal maps could then be integrated, thereby allowing the rats to compute the CS2-US temporal relationship. Although CS1 had a backward relationship to the US, which accounted for the lack of conditioned responding it produced, CS2 would have a forward, anticipatory relationship to the US due to its forward relationship to CS1.

These and other observations from the Miller laboratory led to the formulation of the temporal coding hypothesis (Savastano \& Miller, 1998). The temporal coding hypothesis has four tenets:

(1) Contiguity alone is necessary and sufficient for the formation of an association. (2) The temporal relationship between the associated events is automatically encoded as part of the association (i.e., subjects form temporal maps that link events in memory). (3) This temporal information plays a critical role in the nature, magnitude, and timing of the conditioned response elicited when one of the associates is presented subsequently. Finally, (4) animals can superimpose temporal maps when elements common to these maps are presented together, even when the elements were trained separately. That is, temporal information from different training situations can be integrated. (Savastano \& Miller, 1998, p. 151)

Evidence for temporal integration comes from studies of sensory preconditioning and second-order conditioning (e.g., Barnet, Cole, \& Miller, 1997; Matzel et al., 1988), simultaneous conditioning (e.g., Barnet, Arnold, \& Miller, 1991; Matzel et al., 1988), trace conditioning (e.g., Cole, Barnet, \& Miller, 1995), and conditioned inhibition (e.g., Barnet \& Miller, 1996a, 1996b; Burger, Denniston, \& Miller, 2001; Cole \& Miller, 1999; Denniston, Blaisdell, \& Miller, 1998, 2004; Denniston, Cole, \& Miller, 1998).

Although this evidence is compelling, one could raise the criticism that the evidence described above fails to provide adequate evidence for temporal integration. All of the studies above measured the amount of suppression of licking in the presence of the test CS and used the magnitude of suppression as a proxy for the integrated temporal relationship between CS2 and the US. This indirect measure does not provide a demonstration that the expected time of US occurrence is present in the subject's response to CS2, which would constitute strong and sufficient evidence for temporal integration in higher order conditioning. Instead, observations of strong conditioned lick suppression to a second-order signal for shock were used to infer that the temporal relationship between paired stimuli had been acquired during training, and were integrated to form a temporal map between CS2 and the US. At present, the external validity or generality of temporal integration in rats is threatened by the lack of procedures utilizing a measure other than conditioned lick suppression.

The goals of the present experiments were twofold. The first was to provide evidence for the expectation of the US directly in the conditioned response during CS2. The second was to establish the generality of temporal integration through assessment with a procedure other than conditioned lick suppression. A variant of a fixedinterval schedule of operant conditioning known as the peak procedure has been used to document control over the timing of an instrumental response by the location of the reinforcer relative to the onset of a signal. The maximum rate of responding is located (i.e., it peaks) at the expected time of reinforcement during the signal (Catania, 1970; Roberts, 1981). Here we report an appetitive Pavlovian procedure conceptually related to the peak procedure, which we use to record the response during CS2 following sensory preconditioning. We manipulate the temporal relationship between CS1 and CS2 while holding fixed the temporal relationship between CS1 and the US. On the basis of the temporal coding hypothesis, we can predict the location of the peak rate of responding during tests with CS2. Two experiments manipulated the temporal location of a short-duration CS1 embedded within a long-duration CS2 to influence the timing of conditioned magazine entry during CS2 at test. Our results support the temporal coding hypothesis by showing temporal control of the conditioned response during CS2 by the CS2-CS1 and CS1-US intervals. This temporal control provides strong evidence for temporal integration in appetitive Pavlovian conditioning.

\section{EXPERIMENT 1}

The design for Experiment 1 is depicted in the top panel of Figure 1. All subjects received presentations of an AX compound CS in Phase 1 of sensory preconditioning. CS A was $60 \mathrm{sec}$ in duration, and CS X was $10 \mathrm{sec}$ in duration. In Group Early, CS X was presented during the early portion of CS A, whereas in Group Late, CS X was presented in the latter portion of CS A. In Phase 2, all subjects received simultaneous presentations of a 10 -sec CS X and 10-sec sucrose US (both stimuli onset and terminated together). The temporal coding hypothesis predicts that 


\section{Design of Experiment 1}

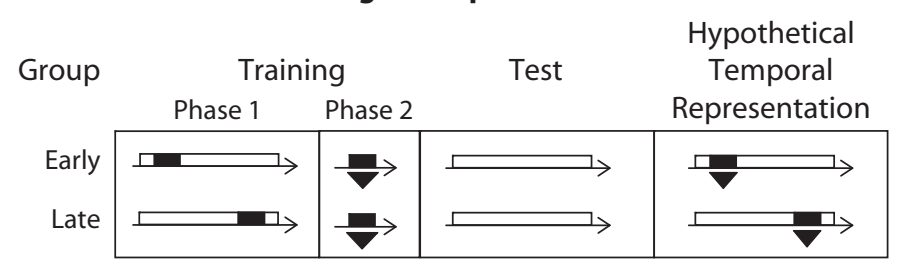

Design of Experiment 2

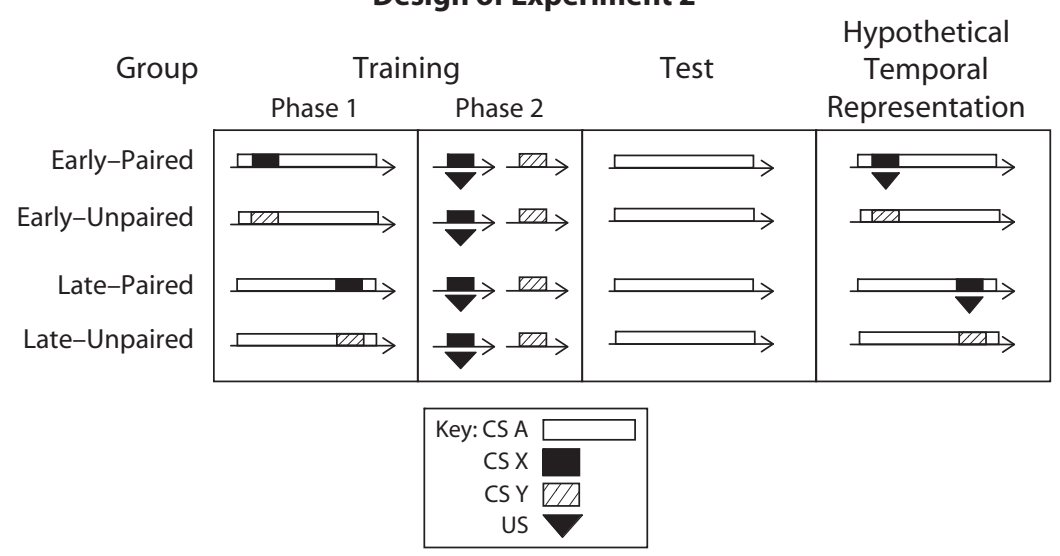

Figure 1. Design and hypothetical temporal representations of Experiment 1 (top panel) and Experiment 2 (bottom panel). In Experiment 1, CS A was a 60-sec tone or noise (counterbalanced within group) and CS X was a 10-sec flashing light. In Experiment 2, CS A was a 60-sec tone and CSs $X$ and $Y$ were a 10-sec flashing light and a 10 -sec click train (counterbalanced within group). The US was 10-sec access to sucrose solution. The rightmost panels represent the hypothetical temporal representations produced by integrating Phase 1 and Phase 2 temporal maps, and the arrows represent the flow of time within a trial (see text for details).

the rats will encode the $\mathrm{A}-\mathrm{X}$ and $\mathrm{X}-\mathrm{US}$ temporal maps and that these temporal maps will be integrated, allowing subjects to compute an A-US temporal relationship. The A-US temporal map should determine the peak time of magazine entry during CS A at test. Thus, we predicted response rates to peak during the early portions of CS A in Group Early and during the latter portions of CS A in Group Late.

\section{Method}

\section{Subjects}

Thirty-two experimentally naive female Long-Evans rats obtained from Harlan Laboratories (Indianapolis) served as subjects. They were pair housed in translucent plastic tubs with a substrate of wood shavings in a vivarium maintained on a 12:12-h light:dark cycle. All experimental manipulations were conducted during the dark portion of the cycle. A progressive food restriction schedule was imposed over the week prior to the beginning of the experiment, until each rat received $15 \mathrm{~g}$ of food each day. All animals were handled daily for $30 \mathrm{sec}$ during the week prior to the initiation of the study. Subjects were randomly assigned to one of two groups (early and late, $n \mathrm{~s}=16$ ).

\section{Apparatus}

Each of eight experimental chambers measuring $30 \times 25 \times 20 \mathrm{~cm}$ (length $\times$ width $\times$ height) was housed in a separate sound- and light-attenuating environmental isolation chest (Med Associates). The walls and ceiling of the chamber were constructed of clear
Plexiglas, and the floor was constructed of stainless steel rods measuring $0.5 \mathrm{~cm}$ in diameter and spaced $1.5 \mathrm{~cm}$ center to center. All experimental procedures were conducted with the houselight on, except where otherwise noted. Each chamber was equipped with a dipper that could deliver sucrose solution $(20 \%)$. When in the raised position, a small well $(0.05 \mathrm{cc})$ at the end of the dipper arm protruded up into the drinking niche. Three speakers on the outside walls of the chamber could deliver a high-frequency tone $(3000 \mathrm{~Hz})$ $8 \mathrm{~dB}(\mathrm{~A})$ above background, a white noise stimulus $8 \mathrm{~dB}(\mathrm{~A})$ above background, and a click train $(6 / \mathrm{sec}) 8 \mathrm{~dB}(\mathrm{~A})$ above background. (Note that the click train was used in Experiment 2, but not Experiment 1.) A flashing light (.25 sec on/.25 sec off) could be presented by a light bulb on the rear wall of the chamber, $13 \mathrm{~cm}$ above the floor of the chamber. The houselight was turned off during the flashing light presentation. Ventilation fans in each enclosure and a whitenoise generator on a shelf outside of the enclosures provided a constant 74- $\mathrm{dB}(\mathrm{A})$ background noise.

\section{Procedure}

Magazine training. On Day 1, rats were acclimated to the apparatus in one 60-min session. During this session, the rats were trained to approach and drink from the dipper when it was raised. Sucrose solution was delivered according to a discrete uniform distribution from 5 to $35 \mathrm{sec}$ in steps of $5 \mathrm{sec}$. Reinforcement consisted of 10 -sec access to the raised dipper cup containing sucrose solution.

Preexposure. On Day 2, rats received four presentations each of CSs A and X per daily 60-min session in an interspersed fashion with a discrete uniform distribution from 2.5 to $6.5 \mathrm{~min}$ (sampled randomly without replacement) in steps of $1 \mathrm{~min}$ (measured from CS termination from one trial to CS onset on the next trial). A 60-sec 
tone served as CS A for half of the rats in each group, and a 60-sec noise served as CS A for the remaining rats in each group. A 10-sec flashing light served as CS X. No reinforcement was delivered during these sessions.

Phase 1 (sensory preconditioning). On Days $3-5$, all subjects received six AX trials in each daily 60 -min session. In Group Early, CS X onset $5 \mathrm{sec}$ after the onset of CS A, whereas in Group Late, CS X onset $45 \mathrm{sec}$ after the onset of CS A. Trials were presented with a discrete uniform distribution from 2 to $8 \mathrm{~min}$ in steps of $1 \mathrm{~min}$. No sucrose or other nominal stimuli were delivered during these sessions.

Magazine training. On Day 6, rats received a magazine training session identical to that received on Day 1 to increase baseline levels of magazine entry prior to Phase 2 conditioning.

Phase 2 (first-order conditioning). On Days 7-12, all subjects received 10 simultaneous presentations of CS X and sucrose in each daily 60-min session. CS X and sucrose onset together and were $10 \mathrm{sec}$ in duration. Trials were presented with discrete uniform distribution from 4 to $8 \mathrm{~min}$ in steps of $1 \mathrm{~min}$.

Probe tests. On Days 13 and 14, rats received four 60-sec nonreinforced probe trials of CS A at 13.5, 27.5, 35, and 48.5 min into each 60-min session. The number of magazine entries was recorded during each presentation of CS A in 1-sec bins.

\section{Results and Discussion}

To assess acquisition of nosepoking during CS X in Phase 2, a discrimination ratio was calculated by dividing $\mathrm{CS}$ responses by the total responses during the CS and a 10 -sec pre-CS interval immediately prior to the delivery of the CS. Because acquisition of an X-US association should be necessary for temporal integration, we wished to remove subjects for which $\mathrm{CS} X$ failed to acquire behavioral control in Phase 2. An outlier analysis was conducted to remove from the experiment subjects with acquisition scores two standard deviations below their respective group means on the final day of acquisition. Data from 4 subjects were removed for this reason, resulting in a final $n$ of 14 for each group. Both groups acquired the discrimination at the same rate. This was supported by a one-way repeated measures ANOVA conducted on discrimination ratios during acquisition with group (early or late) as a between-subjects factor and session (1-6) as a repeated measure. This analysis found a main effect only for session $[F(5,130)=3.85, p<.01]$, and no interaction between session and group $(F<1.0)$. The mean discrimination ratio for the last two days of Phase 2 revealed no difference between Groups Early $(M=.63$, $S D=.06)$ and Late $(M=.68, S D=.08)[t(26)=-1.95$, $p>.05]$. The mean pre-CS response rates were also similar in Groups Early $(M=4.1 \mathrm{sec}, S D=1.75 \mathrm{sec})$ and Late $(M=3.5 \mathrm{sec}, S D=1.23 \mathrm{sec})[t(26)=1.09, p>$ $.05]$, indicating no group differences in baseline levels of responding.

Figure 2 shows mean normalized magazine entries during CS A pooled across both test sessions as a function of time during the CS (1-sec bins) for Groups Early and Late. A higher percentage of magazine entries occurred during early portions of CS A in Group Early than in Group Late, whereas a higher percentage of magazine entries occurred during later portions of CS A in Group Late than in Group Early. A mixed ANOVA conducted on mean normalized magazine scores during CS A revealed a main effect of bin $[F(59,1534)=2.93, p<.01]$. The interaction between bin and group was not reliable $[F(59,1543)=1.23$, $p>.05]$.

The failure to find an interaction may have been due to the large degree of overlap in normalized response rates at intervals during which we did not predict group differences. Our specific predictions were that response rates during CS A should differ between Groups Early and Late at the temporal locations at which the US was expected in one or the other group. According to the temporal coding hypothesis, the US should be expected from 6 to $15 \mathrm{sec}$ following the onset of CS A in Group Early, and

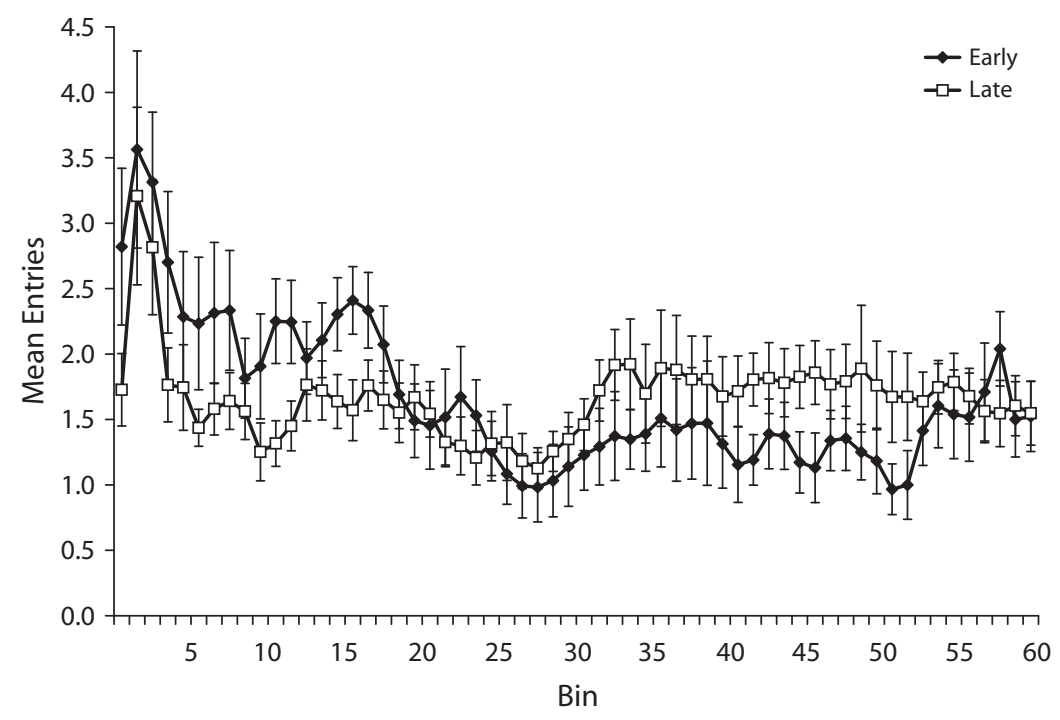

Figure 2. Mean normalized magazine entries during CS A at test (in 1-sec bins) for Groups Early (filled symbols) and Late (open symbols) of Experiment 1. Error bars represent standard errors of the normalized means. 
from 46 to $55 \mathrm{sec}$ following the onset of CS A in Group Late. A similar ANOVA conducted on mean normalized responses during these intervals revealed a group $\times$ bin interaction $[F(19,494)=2.28, p<.001]$, and no main effects. Planned comparisons using the error term from the interaction conducted on each 10 -sec interval revealed higher responding in Group Early than in Group Late during the 6- to 15 -sec interval $[F(1,26)=5.31, p<.05]$, but no group differences during the 46- to 55 -sec interval $[F(1,26)=2.95, p>.05]$.

The results of Experiment 1 provide partial evidence that subjects had encoded the A-X and X-US temporal maps during Phases 1 and 2, respectively, and integrated these maps to form an A-US temporal map. Responding during CS A at test was higher in Group Early than in Group Late during the early interval, but the reverse tended to be true only in the second interval. There also appeared to be a large degree of responding immediately after the onset of CS A at test in both groups. Perhaps this high rate of responding following the onset of the cue was due to pseudoconditioning or sensitization. Such processes could be induced by the onsets of cues in an appetitive context (e.g., the conditioning chamber) or through generalization of responding from CS X to CS A. In Experiment 2, we replicated the design of Experiment 1 and included unpaired control groups in order to assess these possibilities. More importantly, these groups allowed us to test the necessity of first-order X-US pairings for temporal integration.

\section{EXPERIMENT 2}

The design of Experiment 2 is depicted in the bottom panel of Figure 1. In Phase 1 of Experiment 2, subjects in Groups Early-Paired and Late-Paired received AX pairings, with CS X occurring early or late, respectively, during CS A. Subjects in Groups Early-Unpaired and Late-Unpaired received AY pairings in an analogous fashion. In Phase 2, all subjects received simultaneous presentations of CS X and a sucrose US interspersed among nonreinforced presentations of CS Y. At test, all subjects were tested on CS A. Temporal control over responding by CS A was expected only for subjects in Groups EarlyPaired and Late-Paired, in which response rates should peak early and late, respectively.

\section{Method \\ Subjects and Apparatus \\ The experiment was conducted in two replications of equal $n$. Subjects of the same type and maintained in the same way as in Ex- periment 1 were used. Subjects were assigned to one of four groups, early-paired, late-paired, early-unpaired, and late-unpaired ( $n \mathrm{~s}=$ $20 ; n=10$ per replication). The apparatus was the same as that used in Experiment 1.}

\section{Procedure}

Magazine training. Day 1, as in Experiment 1.

Preexposure. Day 2, as in Experiment 1.

Phase 1 (sensory preconditioning). On Days $3-5$, subjects in Group Early-Paired received trials on which CS X onset $5 \mathrm{sec}$ after the onset of CS A. Subjects in Group Late-Paired received trials on which CS X onset $45 \mathrm{sec}$ after the onset of CS A. Subjects in Groups Early-Unpaired and Late-Unpaired received analogous treatment but with CS Y instead of CS X. In all groups, there were six trials in each 60-min session. The light and click were $10 \mathrm{sec}$ in duration and served as CSs X or Y, counterbalanced within groups. The 60sec tone served as CS A for all subjects. Trials were distributed as in Experiment 1.

Magazine training. On Day 6, as in Experiment 1.

Phase 2 (first-order conditioning). On Days 7-12, all subjects received 10 simultaneous presentations of 10 -sec CS X and 10-sec sucrose as in Experiment 1, interspersed among 10 nonreinforced presentations of 10 -sec CS Y in each daily 60 -min session. Trial order was randomized, with the constraint that the same type of trial could not occur more than twice consecutively. Trials occurred with a discrete uniform distribution from 2 to $4 \mathrm{~min}$ with steps of $1 \mathrm{~min}$, sampled randomly without replacement.

Probe tests. On Days 13 and 14, as in Experiment 1.

\section{Results and Discussion}

To determine the acquisition of conditioned responding to CS X during Phase 2, a discrimination ratio was calculated for each subject for each session as $\mathrm{R}=(\mathrm{X}-\mathrm{Y}) /(\mathrm{X}+\mathrm{Y})$, in which the total magazine responses during CS Y in the session were subtracted from total responses during CS X in the session, and this difference was then divided by the sum of responses during CS X and CS Y in the session. Prior to factorial analysis, an outlier analysis was conducted to remove from the experiment subjects with discrimination scores two standard deviations below their respective group means on the final day of acquisition. Data from 6 subjects were removed for this reason. This removal resulted in a final $n$ of 17 for Group Early-Unpaired, and an $n$ of 19 each for Groups Early-Paired, Late-Paired, and Late-Unpaired. All groups acquired the discrimination at the same rate. This was supported by a two-way mixed ANOVA conducted on discrimination ratios during Phase 2 acquisition with group and replication as between-subjects factors and session as a repeated measure. This analysis found a main effect only for session $[F(5,325)=8.38, p<.001]$, and no interactions $(F \mathrm{~S}<1.0)$. No main effect of replication was found, and it did not enter into any higher order interactions. The mean discrimination ratios for the final two sessions of Phase 2 indicated no difference between groups: early-paired ( $M=$ $.44, S D=.19)$, early-unpaired $(M=.48, S D=.22)$, latepaired $(M=.46, S D=.17)$, and late-unpaired $(M=.46$, $S D=.22)[F(3,70)<1]$.

Figure 3 shows mean normalized magazine entries during CS A in the paired (top panel) and unpaired (bottom panel) conditions pooled across all test sessions grouped into 1-sec bins. Rates of magazine entry during the early portions of CS A were higher for Group Early-Paired than for Group Late-Paired, but no difference was found between Groups Early-Unpaired and Late-Unpaired. During the latter portion of CS A, rates of magazine entry were higher for Group Late-Paired than for Group EarlyPaired, and again no difference was observed between Groups Late-Unpaired and Early-Unpaired. A mixed ANOVA conducted on mean normalized magazine responses during CS A at test with group (early or late) and treatment (paired or unpaired) as between-subjects factors 

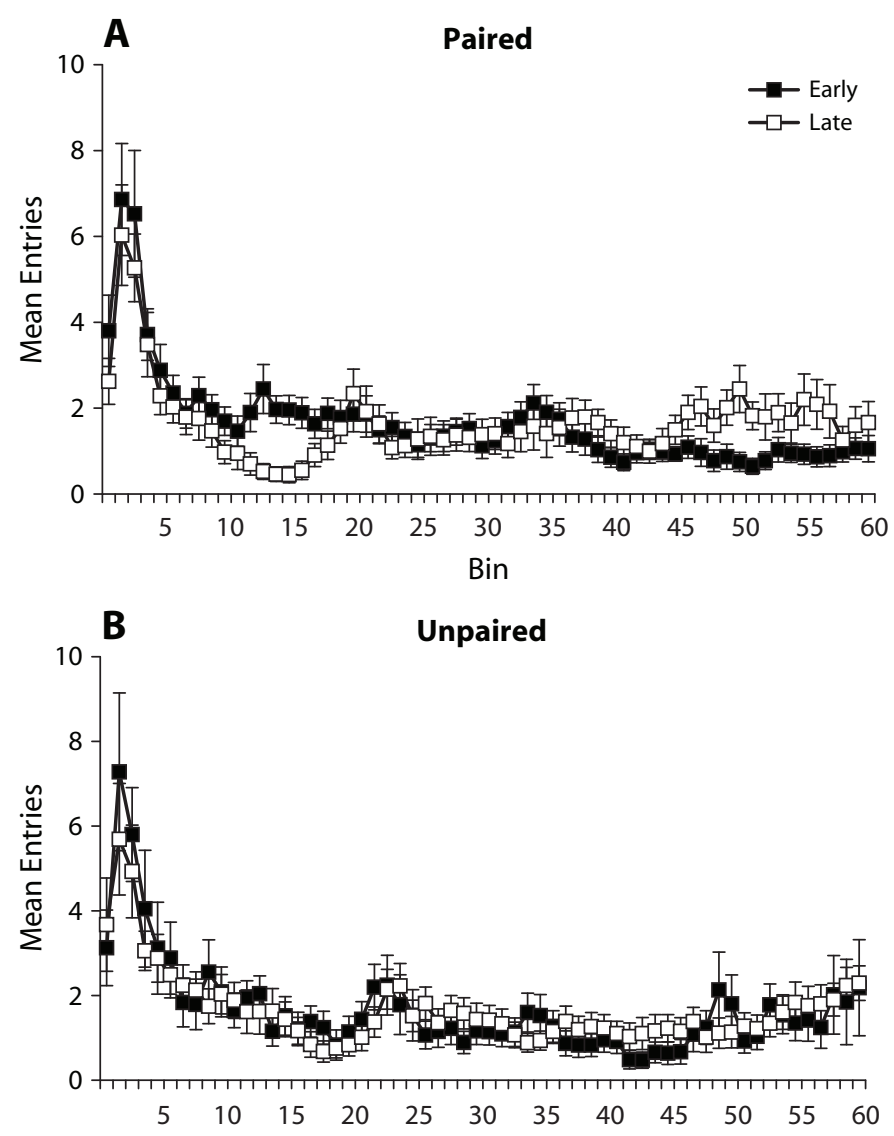

Figure 3. Mean normalized magazine entries during $\mathrm{CS} A$ at test (in 1-sec bins) for Groups Early (filled symbols) and Late (open symbols) separately for the paired (A) and unpaired (B) groups of Experiment 2. Error bars represent standard errors of the normalized means.

and with bin (1-60) as the repeated measure revealed a main effect of bin $[F(59,4130)=15.18, p<.001]$. No other main effects or interactions were significant.

A similar analysis conducted on mean normalized magazine entries at intervals from 6 to $15 \mathrm{sec}$ and from 46 to $55 \mathrm{sec}$ revealed a main effect of bin $[F(19,1330)>2.46$, $p<.001$, a two-way interaction between bin and group $[F(19,1330)>2.06, p<.01]$, and a three-way interaction of bin, group, and treatment $[F(19,1330)>2.05, p<$ $.01]$. The bin $\times$ group interaction resulted from higher responses during Bins 6-15 sec in the early groups than in the late groups, and the reversal to higher responses during Bins 46-55 sec in the late groups than in the early groups. To isolate the source of the three-way interaction, planned comparisons were conducted using the error term from the three-way interaction. These revealed higher rates of responding during Bins $6-15 \mathrm{sec}$ in Group Early-Paired than in Group Late-Paired $[F(1,70)=7.10, p<.01]$, but no difference between Groups Early-Unpaired and Late-Unpaired $(F<1)$. Group Late-Paired responded more than did Group Early-Paired during Bins 46-55 sec $[F(1,70)=11.28, p<.01]$, but no difference in responding was found between Groups Late-Unpaired and EarlyUnpaired $(F<1)$. As in Experiment 1, we observed high rates of responding during the initial few seconds following the onset of the test CS. This was true for subjects in the paired and in the unpaired groups, and it suggests nonconditioned responding elicited by the onset of the CS and not responding controlled by the specific associative training histories.

This experiment provides strong evidence for temporal integration. Response rates during CS A (a CS2) at test were highest at the time when the US should have been expected for both groups in which CS A had been paired with CS X (a CS1). The fact that no temporal control was observed for groups in which CS A had been presented in compound with CS Y (an unpaired stimulus), for which no association with sucrose had been established, shows that both $\mathrm{A}-\mathrm{X}$ and $\mathrm{X}$-sucrose pairings were necessary for the development of temporal control by CS A at test. This temporal control could only come from an A-sucrose temporal map computed from the $\mathrm{A}-\mathrm{X}$ and $\mathrm{X}$-sucrose temporal maps.

\section{GENERAL DISCUSSION}

In Experiment 1, the temporal location at which a short CS1 was presented in compound with a long CS2 during 
Phase 1 of sensory preconditioning influenced the timing of the response to CS2 at test. Experiment 2 replicated this effect more strongly and established that CS1-US pairings were necessary for temporal integration. These results are consistent with those obtained from lick-suppression experiments and support the temporal coding hypothesis. Specifically, they support the tenet that temporal maps are formed between paired events during conditioning, such as between CS2 and CS1 and between CS1 and the US in a sensory preconditioning design. Furthermore, the results support the tenet that temporal maps acquired from separate experiences can be combined to produce an integrated temporal map between associates that have never been paired. In our studies, this consisted of the integration of the CS2-CS1 map with the CS1-US map. Temporal integration allows the subject to compute a CS2-US temporal map. Beyond serving as replications, the present studies strengthen the claims derived from the lick-suppression studies. This strength comes from the demonstration that the timing of the conditioned response elicited by CS2 at test is controlled by the expected time of US delivery encoded by the CS2-US temporal map. These results also establish the generality of temporal integration through its demonstration in an appetitive procedure.

Arcediano, Escobar, and Miller (2003) found evidence in human participants for temporal integration directly in the timing of the response to stimulus with a second-order relationship to the outcome at test. In their study, participants observed simple visual graphics (each $5 \mathrm{sec}$ in duration) presented on a computer screen. All participants received presentations of $\mathrm{S} 2$ forward paired with $\mathrm{S} 1$ in the first observation phase $(\mathrm{S} 2 \rightarrow \mathrm{S} 1)$, followed in a second observation phase by pairing $\mathrm{S} 1$ with an outcome $(\mathrm{S} 1 \rightarrow \mathrm{O})$ in the experimental groups. When presented with $\mathrm{S} 2$ at test, participants were instructed to press the space bar on the computer keyboard at the time when they expected the outcome to appear on the screen. The timing of the keypresses conformed to predictions of the temporal coding hypothesis, showing that participants integrated the Phase 1 and 2 temporal maps, enabling them to compute an S2-O temporal map.

The present results and those of Arcediano et al. (2003) demonstrate the generality of temporal integration in Pavlovian conditioning tasks in rats and humans. Furthermore, our results establish that temporal integration in rats is not restricted to the conditioned suppression procedure employed by Miller and colleagues, but that it can also be demonstrated in an appetitive conditioning procedure as well. The appetitive procedure can be usefully applied to the study of the psychological, pharmacological, and neural mechanisms of timing and associative learning. For example, the dopamine system is involved in many aspects of timing event-outcome relationships (Buhusi \& Meck, 2002; Drew, Fairhurst, Malapani, Horvitz, \& Balsam, 2003; Gibbon, Malapani, Dale, \& Gallistel, 1997). The present procedure could be used to investigate the role of dopamine in timing event-event relationships in Pavlovian conditioning (e.g., between two CSs in Phase 1 of sensory preconditioning) and in the integration of temporal relationships between CS2 and the US.
We have also demonstrated a similar role for higher order associative processes in spatial integration. Blaisdell and Cook (2005) used an analogue to the Pavlovian sensory preconditioning procedure to study the integration of spatial maps in an open-field search task in pigeons. Pigeons were trained to find food randomly hidden in 1 of 16 locations. On sensory preconditioning trials, pigeons were presented with two visual landmarks (LM2 and LM1) placed on the floor of the open field with a stable spatial relationship to each other, allowing them to acquire the LM2 $\rightarrow$ LM1 spatial relationship. Subsequently, LM1 was placed at a fixed distance and direction from a hidden food goal, allowing the pigeons to use the LM1 $\rightarrow$ goal spatial relationship to find the food. Pigeons then received nonreinforced probe tests with LM2 alone. If they had encoded the LM2 $\rightarrow$ LM1 and LM1 $\rightarrow$ goal spatial maps, they could have integrated the maps to form an LM2 $\rightarrow$ LM1 $\rightarrow$ goal spatial map, from which they could compute an LM2 $\rightarrow$ goal map. The novel LM2 $\rightarrow$ goal spatial map could guide the pigeons to search at a specific location within the arena. Blaisdell and Cook found that subjects searched at the location that would be expected if they had integrated the two spatial maps. Sawa et al. (2005) replicated these results using a spatial-search task presented on a touch-screen-equipped monitor. These experiments provide additional evidence that higher order associative processes serve as a mechanism by which spatial maps are formed (see also Chamizo, Rodrigo, \& Mackintosh, 2006). Converging evidence from experiments exploring both temporal and spatial integration advocates a more general role for higher order associative processes in building complex cognitive representations from simpler ones. Consistent with this view, research in humans (Hagmayer \& Waldmann, 2000; Perales et al., 2004) and rats (Blaisdell et al., 2006) has also shown that humans and rats, respectively, can build higher order causal models involving one cause (C) and two effects (E1 and E2) after separate $\mathrm{C} \rightarrow \mathrm{E} 1$ and $\mathrm{C} \rightarrow \mathrm{E} 2$ pairings.

\section{AUTHOR NOTE}

Support for this research was provided by NIMH Grant MH 070633 to A.P.B. and a grant from the Japanese Ministry of Education, Culture, Sports, Science and Technology to K.S. We thank Cory Fischer for assistance with data collection and entry. Thanks go to David Stahlman, Mike Parenteau, and Caitlin Crowley, as well as two anonymous reviewers, for comments on a preliminary draft of this article, and to Peter Balsam for discussions of these studies. This research was conducted following the relevant ethics guidelines for research with animals and was approved by UCLA's institutional IACUC. Requests for reprints should be addressed to A. P. Blaisdell, UCLA Department of Psychology, 1285 Franz Hall, Box 951563, Los Angeles, CA 90095-1563 (e-mail: blaisdell@psych.ucla.edu).

\section{REFERENCES}

Arcediano, F., Escobar, M., \& Miller, R. R. (2003). Temporal integration and temporal backward associations in human and nonhuman subjects. Learning \& Behavior, 31, 242-256.

Barnet, R. C., Arnold, H. M., \& Miller, R. R. (1991). Simultaneous conditioning demonstrated in second-order conditioning: Evidence for similar associative structure in forward and simultaneous conditioning. Learning \& Motivation, 22, 253-268.

Barnet, R. C., Cole, R. P., \& Miller, R. R. (1997). Temporal integration in second-order conditioning and sensory preconditioning. Animal Learning \& Behavior, 25, 221-233. 
Barnet, R. C., \& Miller, R. R. (1996a). Second-order excitation mediated by a backward conditioned inhibitor. Journal of Experimental Psychology: Animal Behavior Processes, 22, 279-296.

BARNET, R. C., \& MILLER, R. R. (1996b). Temporal encoding as a determinant of inhibitory control. Learning \& Motivation, 27, 73-91.

Blaisdell, A. P., \& CoOK, R. G. (2005). Integration of spatial maps in pigeons. Animal Cognition, 8, 7-16.

Blaisdell, A. P., Denniston, J. C., \& Miller, R. R. (1997). Unblocking with qualitative change of unconditioned stimulus. Learning \& Motivation, 28, 268-279.

Blaisdell, A. P., SAWa, K., Leising, K. J., \& Waldmann, M. R. (2006). Causal reasoning in rats. Science, 311, 1020-1022.

Brogden, W. J. (1939). Sensory pre-conditioning. Journal of Experimental Psychology, 25, 323-332.

Bunusi, C. V., \& MECK, W. H. (2002). Differential effects of methamphetamine and haloperidol on the control of an internal clock. Behavioral Neuroscience, 116, 291-297.

Burger, D. C., Denniston, J. C., \& Miller, R. R. (2001). Temporal coding in conditioned inhibition: Retardation tests. Animal Learning \& Behavior, 29, 281-290.

CATANIA, A. C. (1970). Reinforcement schedules and psychophysical judgments: A study of some temporal properties of behavior. In W. N. Schoenfeld (Ed.), The theory of reinforcement schedules (pp. 1-42). New York: Appleton-Century-Crofts.

Chamizo, V. D., Rodrigo, T., \& Mackintosh, N. J. (2006). Spatial integration with rats. Learning \& Behavior, 34, 348-354.

Cole, R. P., Barnet, R. C., \& Miller, R. R. (1995). Temporal encoding in trace conditioning. Animal Learning \& Behavior, 23, 144-153.

Cole, R. P., \& Miller, R. R. (1999). Conditioned excitation and conditioned inhibition acquired through backward conditioning. Learning \& Motivation, 30, 129-156.

DeNNiston, J. C., BLAisdell, A. P., \& Miller, R. R. (1998). Temporal coding affects transfer of serial and simultaneous inhibitors. Animal Learning \& Behavior, 26, 336-350.

Denniston, J. C., Blaisdell, A. P., \& Miller, R. R. (2004). Temporal coding in conditioned inhibition: Analysis of associative structure of inhibition. Journal of Experimental Psychology: Animal Behavior Processes, 30, 190-202.

Denniston, J. C., Cole, R. P., \& Miller, R. R. (1998). The role of temporal relationships in the transfer of conditioned inhibition. Journal of Experimental Psychology: Animal Behavior Processes, 24, 200-214.

Drew, M. R., Fairhurst, S., Malapani, C., Horvitz, J. C., \& BaLSAM, P. D. (2003). Effects of dopamine antagonists on the timing of two intervals. Pharmacology Biochemistry \& Behavior, 75, 9-15.

Gewirtz, J. C., \& DAVIS, M. (1998). Application of Pavlovian higherorder conditioning to the analysis of the neural substrates of fear conditioning. Neuropharmacology, 37, 453-459.

GewirTZ, J. C., \& DAVIS, M. (2000). Using Pavlovian higher-order conditioning paradigms to investigate the neural substrates of emotional learning and memory. Learning \& Memory, 7, 257-266.

Gibbon, J., Malapani, C., Dale, C. L., \& Gallistel, C. R. (1997). Toward a neurobiology of temporal cognition: Advances and challenges. Current Opinion in Neurobiology, 7, 170-184.

HAGMAYER, Y., \& WALDMANN, M. R. (2000). Simulating causal models: The way to structural sensitivity. In L. R. Gleitman \& A. K. Joshi (Eds.), Proceedings of the Twenty-Second Annual Conference of the Cognitive Science Society (pp. 214-219). Mahwah, NJ: Erlbaum.

Holland, P. C. (1980). Influence of visual conditioned stimulus characteristics on the form of Pavlovian appetitive conditioned responding in rats. Journal of Experimental Psychology: Animal Behavior Processes, 6, 81-97.
Holland, P. C. (1988). Extinction and inhibition in unblocking. Journal of Experimental Psychology: Animal Behavior Processes, 14, 261-279.

HoNIG, W. K. (1981). Working memory and the temporal map. In N. E. Spear \& R. R. Miller (Eds.), Information processing in animals: Memory mechanisms (pp. 167-197). Hillsdale, NJ: Erlbaum.

Jenkins, H. M., \& Moore, B. R. (1973). The form of the auto-shaped response with food or water reinforcers. Journal of the Experimental Analysis of Behavior, 20, 163-181.

MACKINTOSH, N. J. (1975). A theory of attention: Variations in the associability of stimuli with reinforcement. Psychological Review, 82, 276-298.

MATZEL, L. D., Held, F. P., \& Miller, R. R. (1988). Information and expression of simultaneous and backward associations: Implications for contiguity theory. Learning \& Motivation, 19, 317-344.

Miller, R. R., \& BarNet, R. C. (1993). The role of time in elementary associations. Current Directions in Psychological Science, 2, 106-111.

PaVLOV, I. P. (1927). Conditioned reflexes (G. V. Anrep, Trans.). London: Oxford University Press.

Pearce, J. M. (1987). A model for stimulus generalization in Pavlovian conditioning. Psychological Review, 94, 61-73.

Pearce, J. M., \& Hall, G. (1980). A model for Pavlovian learning: Variations in the effectiveness of conditioned but not of unconditioned stimuli. Psychological Review, 87, 532-552.

Perales, J. C., Catena, A. S., \& MALDONADO, A. (2004). Inferring non-observed correlations from causal scenarios: The role of causal knowledge. Learning \& Motivation, 35, 115-135.

Pineño, O., \& Miller, R. R. (2005). Primacy and recency effects in extinction and latent inhibition: A selective review with implications for models of learning. Behavioural Processes, 69, 223-235.

Rescorla, R. A., \& WaGNeR, A. R. (1972). A theory of Pavlovian conditioning: Variations in the effectiveness of reinforcement and nonreinforcement. In A. H. Black \& W. F. Prokasy (Eds.), Classical conditioning II: Current research and theory (pp. 64-99). New York: Appleton-Century-Crofts.

RoBERTS, S. (1981). Isolation of an internal clock. Journal of Experimental Psychology: Animal Behavior Processes, 7, 242-268.

SaVASTano, H. I., \& Miller, R. R. (1998). Time as content in Pavlovian conditioning. Behavioural Processes, 44, 147-162.

Sawa, K., Leising, K. J., \& Blaisdell, A. P. (2005). Sensory preconditioning in spatial learning using a touch screen task in pigeons. Journal of Experimental Psychology: Animal Behavior Processes, 31, 368-375.

STICKNEY, K. J., \& DonAhoE, J. W. (1983). Attenuation of blocking by a change in US locus. Animal Learning \& Behavior, 11, 60-66.

Urushihara, K., WheEler, D. S., \& Miller, R. R. (2004). Outcome pre- and postexposure effects: Retention interval interacts with primacy and recency. Journal of Experimental Psychology: Animal Behavior Processes, 30, 283-298.

WAGNER, A. R. (1981). SOP: A model of automatic memory processing in animal behavior. In N. E. Spear \& R. R. Miller (Eds.), Information processing in animals: Memory mechanisms (pp. 5-47). Hillsdale, NJ: Erlbaum.

WheELER, D. S., Stout, S. C., \& Miller, R. R. (2004). Interaction of retention interval with CS-preexposure and extinction treatments: Symmetry with respect to primacy. Learning \& Behavior, 32, 335-347.

(Manuscript received August 10, 2005; revision accepted for publication November 24,2006 .) 